\title{
Investigating the Condition Monitoring of Gearboxes using Magnetoresistive Sensors
}

\author{
Dr. Rolf Slatter \\ Sensitec GmbH, Lahnau, Germany \\ rolf.slatter@sensitec.com
}

\begin{abstract}
Summary:
Intelligent sensors, that can monitor the condition of critical machine components, are an essential "enabling technology" for availability-oriented Product-Service-Systems (PPS). Furthermore, intelligent sensors can provide information that can be offered as a service. Pay-per-Use business models are now appearing in the machine tool, printing machine and packaging machine industries, which rely on accurate information about machine condition, in order to guarantee an agreed level of machine availability [1,2]. Many different approaches are applied to gather information about the condition of machine elements, such as gears, rolling bearings or ballscrews. Magnetoresistive (MR) sensors in combination with newly developed algorithms open up interesting new opportunities for more cost-effective and accurate condition monitoring.
\end{abstract}

Keywords: Condition Monitoring, Machine Elements, Sensors, Magnetic Sensors, Magnetoresistive effect

\begin{abstract}
A classic approach for condition monitoring of Spur Gears is to measure vibration and an associated method is to measure acoustic emissions. Furthermore, the temperature may be measured or wear debris monitored. [3,4] However, new approaches such as the measurement of "Instantaneous Angular Speed“ (IAS) are gaining in popularity [5]. This method makes special demands of the sensors used. They must not only be small, precise and robust, but must also have a wide bandwidth and a low power requirement. In addition to this, the machine builder often wishes to use existing sensors or measurement points for this extra functionality, that is, they wish to avoid the implementation of additional sensors if possible. Magnetoresistive (MR) sensors fulfil this complex set of requirements to a very high degree [6].
\end{abstract}

For condition monitoring of spur gears, accelerometers mounted on the gearbox housing are still the state of the art. However, these have limitations due to transfer path effects and vibrations caused by other machine elements and the environment. Therefore, to distinguish the damage-related frequencies from noise is a major challenge. Recent research has shown the potentials of measuring IAS for condition monitoring. In previous papers, optical encoders have typically been used to measure IAS $[7,8]$. With MR sensors the IAS can be measured at the gear wheel, i.e. near the source of the damage inside the gearbox, so a high signal to noise ratio can be achieved (see Figures 1 and 2).

In a joint project with the Institute for Product Development and Machine Elements (pmd) of the Technical University of Darmstadt the application of MR sensors for the condition monitoring of gearboxes has been investigated. This paper describes the integration of MR sensors in a single-stage spur gear and presents measurement results from these sensors for both undamaged and damaged conditions (Figure 4). Different measuring positions are evaluated according to measuring concept and location, including the use of a spur gear as measuring standard (see Figure 3). A comparison of the acquired IAS signals to accelerometer measurements shows that MR sensors are a promising alternative to conventional vibration measurement. Finally, an outlook of further condition monitoring applications of MR sensors is shown.

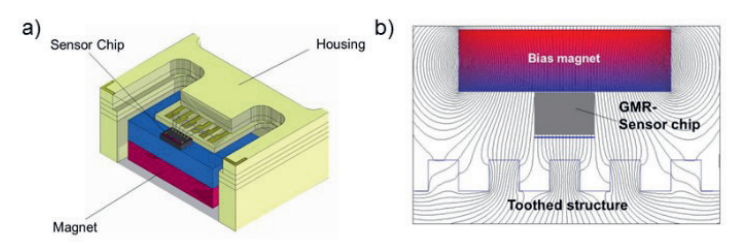

Fig. 1: GMR Tooth Sensor Module (Source: Sensitec $\mathrm{GmbH})$ 


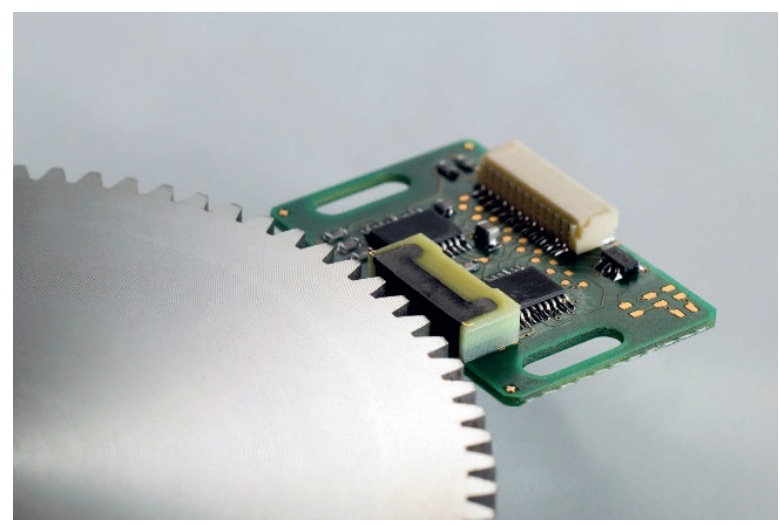

Fig. 2: Application Example (Source: Sensitec $\mathrm{GmbH}$ )

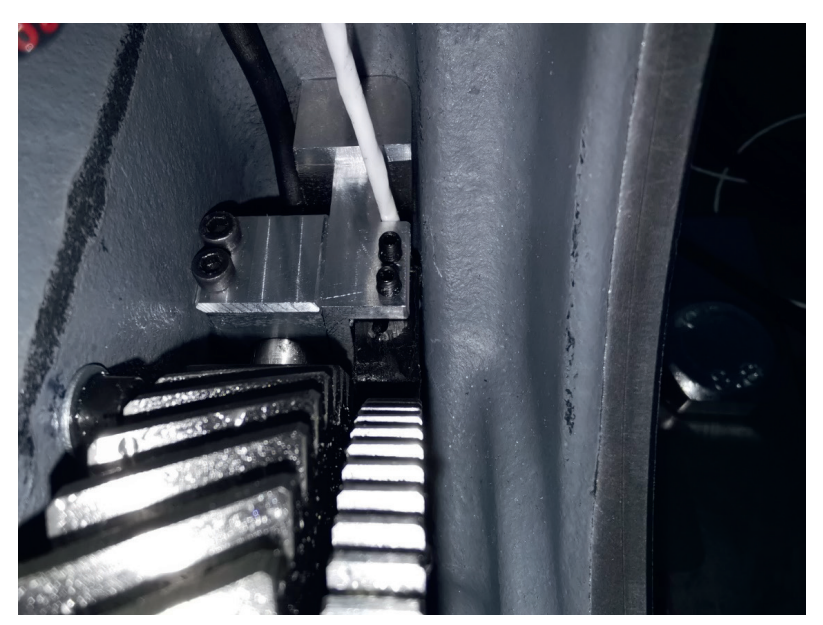

Fig. 3: Implementation of MR sensors using the spur gear as measuring standard (Source: pmd, TU Darmstadt)

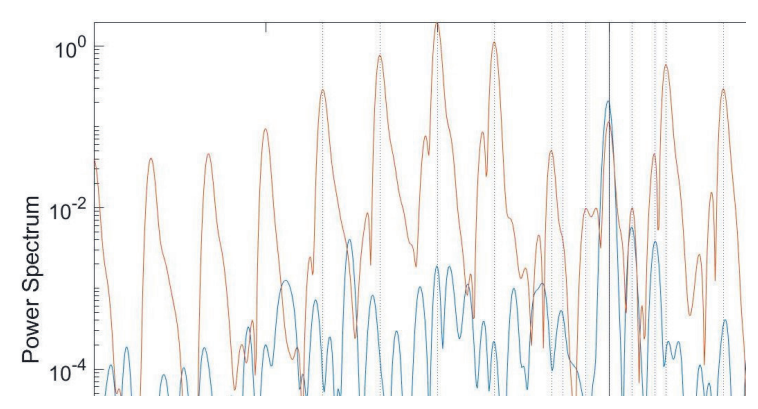

Fig. 4: Spectrum of IAS signal clearly shows sidebands around gearmesh frequency. The spacing of the sidebands correctly indicates a fault on the input shaft side of the gearbox (Source: pmd, TU Darmstadt)

\section{References}

[1] Kölsch, P. et al: "A novel concept for the development of availability-oriented business models", Procedia CIRP 64 (2017) pp. 340 - 344

[2] Schmitt, R. \& Voigtmann, C.; "Sensor information as a service - component of networked production", J. Sens. Sens. Syst., 7, 389-402, 2018

[3] Zeng, Q. et al: "Planetary Gear Fault Diagnosis Based on Instantaneous Angular Speed Analysis", Proc. of 23rd International Conference on Automation and Computing, University of Huddersfield, September 2017

[4] Slatter, R.: "Emerging magnetic sensor technologies for condition monitoring and non-destructive testing", Proc. of Smart Systems Integration Conference, Copenhagen, March 2015

[5] Slatter, R..: "Intelligente Sensoren als Enabler smarter Produktsysteme“, Proc. of SysLM Tagung 2017, Kaiserslautern, October 2017

[6] Wiegel, T. \& Seewig, J.: "Robust wear-detecting sensor concepts to realize innovative services and availability-oriented business models in capital goods industry", Proc. of 14th MRSymposium, Wetzlar, March 2017

[7] Helwig, N.: „Modular Sensor Systems for real time Process Control and Smart Condition Monitoring using XMR sensor technology", Proc. of 14th MR-Symposium, Wetzlar, March 2017

[8] Slatter, R.; "Condition Monitoring of Gearboxes using Magnetoresistive Sensors", Proc. of 8th International Conference on Gears, Munich, September 2019 